\title{
Alterações na composição morfológica em função do estádio de maturação em cultivares de milho para produção de silagem
}

\author{
Maity Zopollatto', Luiz Gustavo Nussio'1, Lucas José Mari ${ }^{1}$, Patrick Schmidt ${ }^{2}$, Aildson Pereira \\ Duarte $^{3}$, Gerson Barreto Mourão 3
}

\author{
${ }^{1}$ Departamento de Zootecnia, USP/ESALQ, Piracicaba-SP. \\ 2 Departamento de Zootecnia, UFPR, Curitiba-PR. \\ ${ }^{3}$ Apta Regional, Assis-SP.
}

RESUMO - Objetivou-se avaliar o teor de matéria seca (MS) e a participação percentual das frações da planta em híbridos de milho colhidos em diversos estádios de maturação. Utilizou-se um delineamento em blocos casualizados, com esquema fatorial $8 \times 6 \times 2$, composto de oito épocas de corte, seis híbridos de milho e duas safras (2001/2002 e 2002/2003). Os híbridos CO 32, AG 5011, P 3041, DKB 333B, AG 1051 e Z 8550 foram colhidos ao atingirem 50\% de florescimento masculino, 15 dias após esta data e, posteriormente, a cada semana, totalizando-se oito cortes. As plantas atingiram o teor de MS para ensilagem (32 a 35\% MS) 92 a 112 dias após a semeadura (DAS). O avanço da maturação aumentou os teores de MS das frações colmo (de 16,9 para 28\%), folha (de 23,2 para 48,8\%), sabugo (de 10,0 para 55,5\%) e grãos (de 50,4 para 70,9\%). Além disso, promoveu aumento das proporções de MS acumulada nos sabugos (de 1,6 para 9,2\%) e grãos (de 0 para 43,4\%) e redução na proporção de colmo (de 63,4 para 29,5\%) e folhas (de 27,5 para 10,8\%). A comparação dos híbridos de milho colhidos em estádios fisiológicos diferentes considerando apenas a participação das frações na planta deve ser feita com muito critério, uma vez que a época de corte pode alterar significativamente a composição morfológica da planta.

Palavras-chave: colmo, época de corte, folhas, grãos, sabugo

\section{Changes in morphological composition according to the maturity stage in corn cultivars for silage production}

\begin{abstract}
The objective of this experiment was to evaluate the dry matter (DM) content and the percent participation of fractions that compose the plant in corn cultivars harvested at different maturity stages. A randomized block design with an $8 \times 6 \times 2$ factorial scheme composed of eight harvesting times, six corn cultivars and two harvest years (2001/2002 and 2002/2003) was used. Cultivars CO 32, AG 5011, P 3041, DKB 333B, AG 1051 and Z 8550 were harvested when they reached 50\% male flowering; 15 days after this date and later, each week, totalizing eight harvesting times. The plants reached the recommended DM content for silage production (32 to 35\% DM) between 92 and 112 days after sowing (DAS) at the evaluated years. The maturity advancement resulted in increases in DM content in stem (from 16.9 to $28 \%$ ), DM content in leaves (from 23.2 to $48.8 \%$ ), DM content in cob (from 10 to 55.5\%), and DM content in grains (from 50.4 to $70.9 \%$ ). Furthermore, it resulted in increases in cob (from 1.6 to $9.2 \%$ ) and grain proportion (from 0 to $43.4 \%$ ), and decrease in stem (from 63.4 to $29.5 \%$ ) and leaves proportion (from 27.5 to $10.8 \%$ ). The corn cultivars showed distinct growing pattern for the evaluated variables. Therefore, plants harvested at different physiologic states can only be compared with fractions participation with considerable discernment, once the harvesting time can modify significantly the plant morphological composition.
\end{abstract}

Key Words: cob, grains, harvesting time, leaves, stem

\section{Introdução}

O elevado valor energético, o baixo teor de fibra, a alta produção de matéria seca por unidade de área, a colheita mecânica facilitada e os bons padrões de fermentação da silagem, sem a necessidade de utilização de aditivos ou présecagem, são características que fazem da planta de milho uma das forragens mais utilizadas em silagens para ruminantes (Pereira et al., 2004).

Na nutrição animal, a planta de milho apresenta dois componentes distintos: a fração vegetativa, composta basicamente de carboidratos estruturais, e a fração granífera, representada principalmente pelo amido do endosperma. Do florescimento ao estádio de grão farináceo, a planta de

Este artigo foi recebido em 2/4/2007 e aprovado em 11/8/2008.

Correspondências devem ser enviadas para:mzopolla@yahoo.com.br 
milho sofre significativa transformação, tanto em quantidade, pelo acúmulo de matéria seca, como em qualidade, em conseqüência da rápida modificação da participação percentual dos componentes da planta (Ferreira, 2001).

O teor de matéria seca da planta no momento da ensilagem depende dos teores de matéria seca dos seus componentes estruturais. Segundo Hunter (1978), a importância da participação dos grãos como principal fator responsável pela qualidade da silagem de milho é questionável, uma vez que existe variação genotípica na qualidade da fração fibrosa da planta expressa pelo consumo de matéria seca e pela digestibilidade da forragem. Esses valores não dependem da proporção de grãos na matéria seca da planta, o que indica que a porção forrageira contribui significativamente para a qualidade.

Neumann et al. (2006) verificaram valores heterogêneos de porcentagem de matéria seca das frações e de composição morfológica da planta e concluíram que não é possível definir um momento padrão de corte mais adequado para silagem.

A fração fibrosa da planta, constituída de colmo, folhas e brácteas, pode representar mais de $50 \%$ da matéria seca da planta, portanto, influencia a produção de matéria seca e o valor nutritivo da planta inteira (Wolf et al., 1993).

Este estudo foi realizado para avaliar as alterações morfológicas de híbridos de milho para produção de silagem, do florescimento até oito semanas subseqüentes, considerando a participação dos seus componentes na planta, a fim de observar o melhor momento de colheita para silagem.

\section{Material e Métodos}

O experimento foi conduzido no Departamento de Zootecnia - Setor de Ruminantes, na USP/ESALQ, em Piracicaba, São Paulo, por dois anos consecutivos (safras 2001/2002 e 2002/2003). Adotou-se o delineamento em blocos ao acaso, com parcelas subdivididas no tempo, composto de quatro blocos e seis híbridos em oito épocas de corte. Os cultivares de milho utilizados foram: CO 32: híbrido triplo, grão semiduro e ciclo precoce; AG 5011: híbrido triplo, grão dentado e ciclo precoce; P 3041: híbrido triplo, grão duro e ciclo precoce; DKB 333B: híbrido simples, grão semiduro e ciclo normal; AG 1051: híbrido duplo, grão dentado e ciclo normal; Z 8550: híbrido triplo, grão semidentado e ciclo precoce.

A semeadura da safra 2001/2002 foi realizada no dia $31 / 11 / 2001$ e a da safra 2002/2003, no dia 3/12/2002. As sementes foram tratadas com o inseticida Futur ${ }^{\circledR}$ (Thiodicarb + micronutrientes) para controle de pragas do solo. $\mathrm{Na}$ semeadura, realizada manualmente, foram colocadas duas sementes por cova a cada $22 \mathrm{~cm}$. A adubação de semeadura foi feita com a fórmula NPK 8-20-20 (350 kg/ha) e as adubações de cobertura foram realizadas 30 e 45 dias após a semeadura, com aplicação da fórmula NPK $20-0-20(300 \mathrm{~kg} / \mathrm{ha})$. A correção do estande foi feita 15 a 30 dias após a semeadura para atingir população de 57.500 plantas/ha.

$\mathrm{O}$ ponto de colheita foi determinado quando todas as parcelas de um mesmo cultivar atingissem 50\% de florescimento masculino ( $50 \%$ das plantas com emissão do pendão), 15 dias após esta data e, posteriormente, a cada semana, totalizando oito cortes. Na safra 2001/2002, os cultivares CO 32, AG 5011, P 3041, DKB 333B, AG 1051 e Z 8550 atingiram $50 \%$ de florescimento aos $67,67,63,70,70$ e 63 dias após a semeadura, respectivamente, enquanto, na safra 2002/2003, o tempo foi de 64, 59, 59, 64, 64 e 59 dias após a semeadura, respectivamente. Com a ocorrência de elevada precipitação na época, o $2^{\circ}$ corte da safra 2002/2003 não foi realizado (Tabela 1).

Após o corte, realizado a $5 \mathrm{~cm}$ do solo, cinco plantas foram separadas ao acaso e pesadas para determinação da massa total para fracionamento das partes (sabugo, grãos, folhas e colmo+bainha+pendão). As amostras foram mantidas em estufas de ventilação forçada a $60^{\circ} \mathrm{C}$, por cerca de 72 horas, para determinação do teor de matéria seca.

Com base nos dados obtidos, além dos teores de matéria seca das frações, realizaram-se os cálculos das proporções de MS acumulada no colmo, nas folhas, no sabugo e nos grãos. Os resultados foram analisados segundo o procedimento PROC MIXED do programa estatístico SAS $^{\circledR}$ versão 9.1.3, em delineamento fatorial $8 \times 6 \times 2 . \mathrm{Na}$ análise descritiva, utilizou-se a variável corte para obtenção das médias. Para a comparação de médias das interações que apresentaram diferenças significativas, foi utilizado o teste $\mathrm{t}$ de Student com o nível de 5\% de probabilidade.

Tabela 1 - Época de corte (dias após a semeadura) dos híbridos de milho avaliados para produção de silagem

\begin{tabular}{|c|c|c|c|c|c|c|c|c|}
\hline \multirow[t]{2}{*}{ Híbrido } & \multicolumn{8}{|c|}{ Corte - safra 2001/2002 } \\
\hline & 1 & 2 & 3 & 4 & 5 & 6 & 7 & 8 \\
\hline $\mathrm{CO} 32$ & 67 & 80 & 88 & 94 & 102 & 109 & 116 & 122 \\
\hline AG 5011 & 67 & 80 & 88 & 94 & 102 & 109 & 116 & 122 \\
\hline P 3041 & 63 & 77 & 84 & 90 & 98 & 105 & 112 & 118 \\
\hline DKB 333B & 70 & 83 & 90 & 98 & 105 & 112 & 118 & 126 \\
\hline AG 1051 & 70 & 83 & 90 & 98 & 105 & 112 & 118 & 126 \\
\hline \multirow[t]{2}{*}{ Z 8550} & 63 & 77 & 84 & 90 & 98 & 105 & 112 & 118 \\
\hline & \multicolumn{8}{|c|}{ Corte - safra 2002/2003 } \\
\hline CO 32 & 64 & - & 84 & 92 & 99 & 105 & 112 & 119 \\
\hline AG 5011 & 59 & - & 80 & 87 & 94 & 101 & 109 & 115 \\
\hline P 3041 & 59 & - & 80 & 87 & 94 & 101 & 109 & 115 \\
\hline DKB 333B & 64 & - & 84 & 92 & 99 & 105 & 112 & 119 \\
\hline AG 1051 & 64 & - & 84 & 92 & 99 & 105 & 112 & 119 \\
\hline Z 8550 & 59 & - & 80 & 87 & 94 & 101 & 109 & 115 \\
\hline
\end{tabular}

(C) 2009 Sociedade Brasileira de Zootecnia 
Os híbridos que apresentaram perfil temporal semelhante, determinado pelo teste $t$ de Student, foram agrupados no momento da elaboração das curvas de regressão. Para a elaboração das equações de regressão, os dados dos teores de matéria seca da folha, do colmo, sabugo e grão, e a proporção destas frações na planta foram analisados estatisticamente considerando as estruturas de co-variâncias mais adequadas para cada variável, em virtude da presença de medidas repetidas. O modelo matemático incluiu os efeitos de híbrido, corte e safra, além do erro experimental. Os resultados são apresentados como médias ajustadas pelo método dos quadrados mínimos.

\section{Resultados e Discussão}

O teor médio de matéria seca da planta (Tabela 2) nas duas safras aumentou $(\mathrm{P}<0,05)$ com o avanço da matu- ridade, passando de $15 \%$ de matéria seca no $1^{\underline{0}}$ corte para aproximadamente $46 \% \mathrm{MS}$ no $8 \mathrm{o}$ corte. A porcentagem de matéria seca da planta de 32 a $35 \%$ recomendada para ensilagem foi atingida 98 a 112 dias após semeadura na safra 2001/2002, e 94 a 105 dias após semeadura na safra 2002/2003, correspondentes ao 5으 6 o cortes, com exceção do híbrido $\mathrm{CO} 32$, que atingiu teor adequado entre o 4 o e 50 cortes (92 a 102 DAS).

A porcentagem de MS do colmo (Tabela 2) quando a planta atingiu os teores recomendados (32 a 35\%) foi de 23 a $25 \%$ na primeira safra e 20 a $23 \%$ na safra $2002 / 2003$, semelhante ao obtido por Neumann et al. (2006), que encontraram 22 a $26 \%$ de MS no colmo no ponto de silagem.

O híbrido CO 32 apresentou teor de MS do colmo diferente dos demais e, portanto, para este material, criou-se uma curva de regressão individual (Figura 1a). No entanto, em todos os híbridos, houve efeito quadrático $(\mathrm{P}<0,01)$ do tempo sobre o teor de MS do colmo.

Tabela 2 - Teor médio de matéria seca das partes da planta dos híbridos de milho avaliados para produção de silagem

\begin{tabular}{|c|c|c|c|c|c|c|c|c|}
\hline \multirow[t]{2}{*}{ Híbrido } & \multicolumn{8}{|c|}{ Corte } \\
\hline & 1 & 2 & 3 & 4 & 5 & 6 & 7 & 8 \\
\hline & \multicolumn{8}{|c|}{ Planta inteira $(\%)$} \\
\hline CO 32 & $16,6 \mathrm{Af}$ & - & $24,4 \mathrm{Ae}$ & $29,6 \mathrm{Ad}$ & $37,8 \mathrm{Ac}$ & $42,7 \mathrm{Ab}$ & $50,4 \mathrm{Aa}$ & $55,8 \mathrm{Aa}$ \\
\hline AG 5011 & $13,0 \mathrm{Df}$ & - & $20,2 \mathrm{Ce}$ & $22,5 \mathrm{Cd}$ & $28,6 \mathrm{Cc}$ & $37,2 \mathrm{Bb}$ & $41,9 \mathrm{Ba}$ & $44,3 \mathrm{~B} \mathrm{a}$ \\
\hline P 3041 & $13,6 \mathrm{Df}$ & - & $19,5 \mathrm{Ce}$ & $23,9 \mathrm{Cd}$ & $29,8 \mathrm{Cc}$ & $33,3 \mathrm{Cb}$ & $41,2 \mathrm{Ba}$ & $37,9 \mathrm{Ca}$ \\
\hline DKB 333B & $15,5 \mathrm{Be}$ & - & $23,2 \mathrm{ABd}$ & $28,7 \mathrm{ABc}$ & $30,1 \mathrm{Cc}$ & $35,7 \mathrm{BCb}$ & $38,1 \mathrm{Bab}$ & $43,2 \mathrm{BCa}$ \\
\hline Erro-padrão & 0,22 & - & 0,46 & 0,78 & 0,94 & 1,63 & 1,92 & 1,80 \\
\hline Safra $2001 / 2002$ & $15,0 \mathrm{~h}$ & $17,8 \mathrm{~g}$ & $20,9 \mathrm{Bf}$ & $26,2 \mathrm{e}$ & $31,7 \mathrm{~d}$ & $36,0 \mathrm{Bc}$ & $39,9 \mathrm{Bb}$ & $45,3 \mathrm{a}$ \\
\hline Safra $2002 / 2003$ & $14,7 \mathrm{f}$ & - & $22,4 \mathrm{Ae}$ & $25,9 d$ & $32,0 \mathrm{c}$ & $37,8 \mathrm{Ab}$ & $44,6 \mathrm{Aa}$ & $46,6 \mathrm{a}$ \\
\hline \multirow[t]{2}{*}{ Erro-padrão } & 0,13 & 0,21 & 0,26 & 0,43 & 0,55 & 0,88 & 1,10 & 1,04 \\
\hline & \multicolumn{8}{|c|}{ Colmo $(\%)$} \\
\hline AG 1051 & $16,7 \mathrm{Ce}$ & - & $19,8 \mathrm{Ad}$ & $21,7 \mathrm{BCc}$ & $21,6 \mathrm{Bc}$ & $25,1 \mathrm{Bb}$ & $23,6 \mathrm{Cb}$ & $27,5 \mathrm{Ba}$ \\
\hline Z 8550 & $17,9 \mathrm{Be}$ & - & $17,8 \mathrm{Be}$ & $21,1 \mathrm{Cd}$ & $23,1 \mathrm{Ac}$ & $24,9 \mathrm{Bb}$ & $28,4 \mathrm{Ba}$ & $26,5 \mathrm{BCab}$ \\
\hline Erro-padrão & 0,33 & - & 0,59 & 0,50 & 0,57 & 0,71 & 0,80 & 0,77 \\
\hline Safra 2002 & $16,9 \mathrm{f}$ & $18,8 \mathrm{e}$ & $19,3 \mathrm{Ae}$ & $21,3 \mathrm{Ad}$ & $23,0 \mathrm{Ac}$ & $25,1 \mathrm{Ab}$ & $25,6 b$ & $28,0 \mathrm{Aa}$ \\
\hline Safra 2003 & $16,9 \mathrm{~d}$ & - & $16,8 \mathrm{Bd}$ & $20,4 \mathrm{Bc}$ & $20,1 \mathrm{Bc}$ & $23,2 \mathrm{Bb}$ & $24,9 \mathrm{a}$ & $25,9 \mathrm{Ba}$ \\
\hline \multirow[t]{2}{*}{ Erro-padrão } & 0,19 & 0,37 & 0,34 & 0,29 & 0,33 & 0,41 & 0,46 & 0,44 \\
\hline & \multicolumn{8}{|c|}{ Folha $(\%)$} \\
\hline CO 32 & $26,6 \mathrm{Ae}$ & - & $25,9 \mathrm{ABe}$ & $25,2 \mathrm{Cd}$ & $32,5 \mathrm{ABd}$ & $40,7 \mathrm{Ac}$ & $56,6 \mathrm{Ab}$ & $76,7 \mathrm{Aa}$ \\
\hline AG 5011 & $24,2 \mathrm{Be}$ & - & $28,3 \mathrm{Ade}$ & $24,9 \mathrm{Cd}$ & $31,1 \mathrm{ABd}$ & $34,8 \mathrm{Bc}$ & $47,0 \mathrm{BCb}$ & $59,5 \mathrm{~B} \mathrm{a}$ \\
\hline P 3041 & $23,9 \mathrm{BCc}$ & - & $22,0 \mathrm{Bc}$ & $24,9 \mathrm{Cb}$ & $30,9 \mathrm{Bb}$ & $29,9 \mathrm{Cb}$ & $43,9 \mathrm{BCa}$ & $47,4 \mathrm{Ca}$ \\
\hline DKB 333B & $22,8 \mathrm{Cd}$ & - & $24,4 \mathrm{ABcd}$ & $27,8 \mathrm{Bc}$ & $26,9 \mathrm{Cc}$ & $34,6 \mathrm{Bb}$ & $34,9 \mathrm{Db}$ & $58,9 \mathrm{Ba}$ \\
\hline
\end{tabular}

Médias seguidas de letras diferentes, maiúscula na coluna ou minúscula na linha, diferem entre si $(\mathrm{P}<0,05)$ pelo teste $\mathrm{t}$ de Student. 


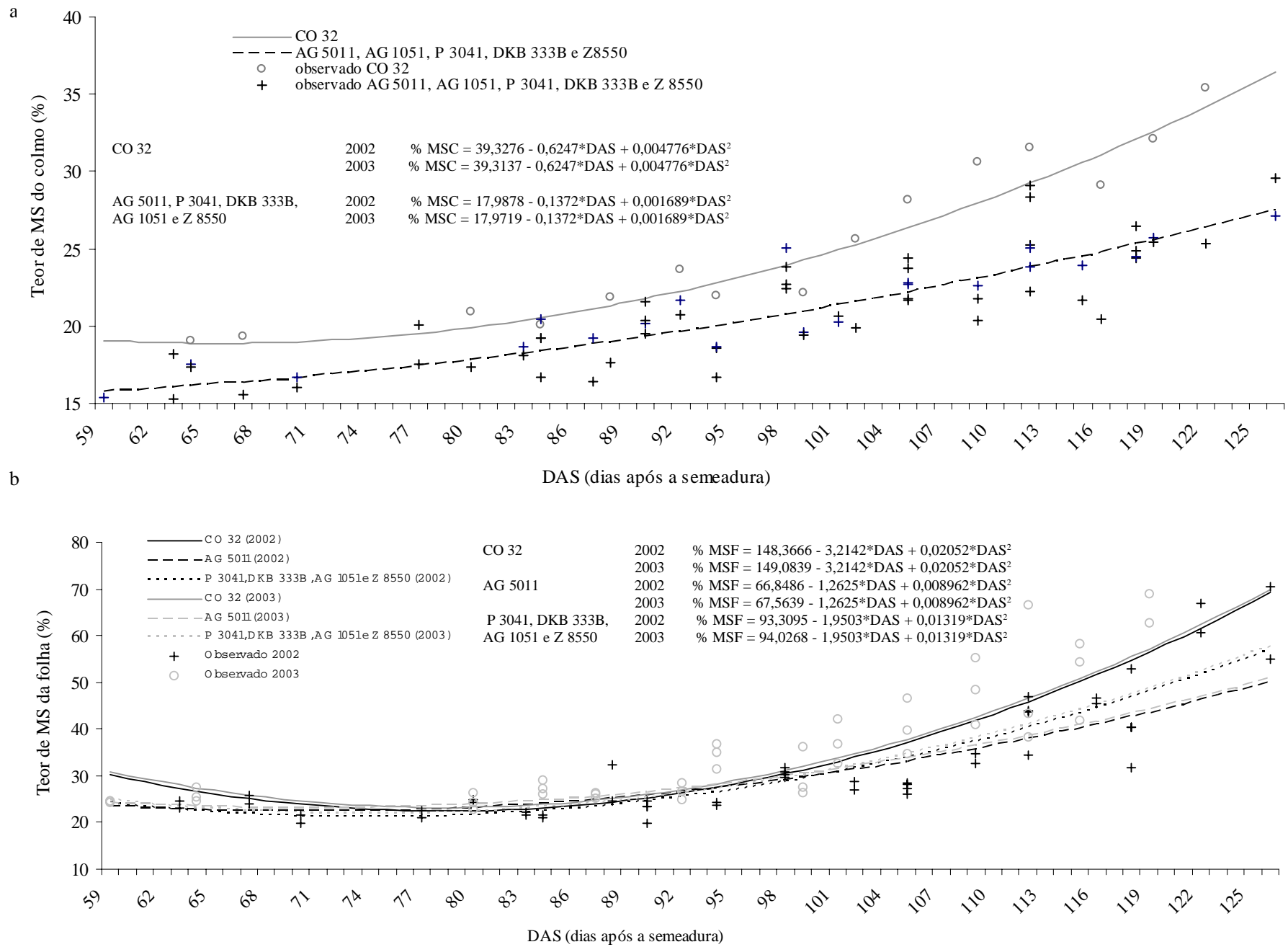

${ }^{1} \mathrm{MSC}$ - teor de MS do colmo; ${ }^{2} \mathrm{MSF}$ - teor de MS da folha; DAS - dias após a semeadura.

Figura 1 - Teor de matéria seca do colmo (a) e da folha (b) em cada época de corte.

A mudança do dreno da planta após o florescimento, da fração fibrosa para a espiga (Ferreira, 2001), alterou a translocação de nutriente, quando o colmo e as demais frações fibrosas passaram a elevar o teor de MS, que atingiu valores de $36,4 \%$ no híbrido CO 32 e $27,5 \%$ nos demais aos 126 DAS. Nos dois anos, os teores de matéria seca da folha elevaram $(\mathrm{P}<0,05)$ a partir do quarto corte, de modo que, em média, a safra 2002/2003 apresentou maiores $(\mathrm{P}<0,05)$ valores (Tabela 2$)$. No ponto de silagem $\left(5^{\circ}\right.$ e $6^{\circ}$ cortes), quando a planta apresentou 32 a $35 \%$ de MS, os teores de MS da folha foram de 28,4 a 33,5\% (2001/2002) e 32,3 a $38,8 \%$ (2002/2003).

Neumann et al. (2006) avaliaram o perfil produtivo de híbridos de milho para produção de silagem, colhidos quando a planta apresentava em média $38,2 \%$ de MS, e observaram teores de MS na folha de 35,5 a 42,5\%. Neste estudo, o híbrido CO 32 foi o que apresentou, em média, os maiores teores de matéria seca da folha, e os híbridos P 3041 e DKB 333B, os menores valores, apesar da oscilação entre os cortes.

Os híbridos P 3041, DKB 333B, AG 1051 e Z 8550 apresentaram perfil semelhante nas safras avaliadas e, por isso, foram agrupados no momento da elaboração das curvas de regressão do teor de matéria seca da folha (Figura 1b).

O efeito quadrático da maturação sobre o teor de MS da folha comprova que, inicialmente, até por volta de 98 DAS, a folha não sofre grandes alterações no seu teor de matéria seca, portanto, até este ponto, sua taxa fotossintética é alta e supera a taxa respiratória, por isso, não há redução do teor de água nesta fração da planta.

O avanço do estádio de maturação nos dois anos de avaliação resultou em aumento $(\mathrm{P}<0,05)$ nos teores de matéria seca do sabugo (Tabela 3), que passaram de 10\% 
Tabela 3 - Teores médios de matéria seca do sabugo e do grão (\%) dos híbridos de milho em cada época de corte

\begin{tabular}{|c|c|c|c|c|c|c|c|c|}
\hline \multirow[t]{2}{*}{ Híbrido } & \multicolumn{8}{|c|}{ Corte } \\
\hline & 1 & 2 & 3 & 4 & 5 & 6 & 7 & 8 \\
\hline \multicolumn{9}{|l|}{ Sabugo (\%) } \\
\hline CO 32 & $11,2 \mathrm{Bd}$ & - & - & - & $44,9 \mathrm{Ac}$ & $47,5 \mathrm{Ac}$ & $51,7 \mathrm{Ab}$ & $55,5 \mathrm{Aa}$ \\
\hline AG 5011 & $17,0 \mathrm{Ac}$ & - & - & - & $40,7 \mathrm{Bb}$ & $41,4 \mathrm{Bb}$ & $43,5 \mathrm{Bab}$ & $45,4 \mathrm{Ba}$ \\
\hline P 3041 & $13,1 \mathrm{Bc}$ & - & - & - & $35,0 \mathrm{Db}$ & $37,0 \mathrm{Cab}$ & $37,2 \mathrm{Cab}$ & $39,8 \mathrm{Ca}$ \\
\hline DKB 333B & $11,2 \mathrm{Bc}$ & - & - & - & $40,1 \mathrm{Bb}$ & $42,2 \mathrm{Bb}$ & $43,0 \mathrm{Bab}$ & $45,3 \mathrm{Ba}$ \\
\hline AG 1051 & $10,0 \mathrm{Bb}$ & - & - & - & $38,8 \mathrm{BCa}$ & $41,3 \mathrm{Ba}$ & $40,6 \mathrm{Ba}$ & $41,0 \mathrm{Ca}$ \\
\hline Z 8550 & $11,9 \mathrm{Bc}$ & - & - & - & $37,0 \mathrm{Cb}$ & $37,6 \mathrm{Cb}$ & $40,9 \mathrm{Ba}$ & $42,0 \mathrm{Ca}$ \\
\hline Erro-padrão & 1,12 & - & - & - & 1,12 & 1,12 & 1,12 & 1,12 \\
\hline \multicolumn{9}{|l|}{ Grão (\%) } \\
\hline CO 32 & - & - & - & - & $58,0 \mathrm{Ab}$ & $64,5 \mathrm{Ab}$ & $61,8 \mathrm{Ab}$ & $76,1 \mathrm{Aa}$ \\
\hline AG 5011 & - & - & - & - & $51,6 \mathrm{Cb}$ & $58,6 \mathrm{Ab}$ & $56,7 \mathrm{Ab}$ & $68,0 \mathrm{Ca}$ \\
\hline P 3041 & - & - & - & - & $53,8 \mathrm{Bb}$ & $60,6 \mathrm{Ab}$ & $56,8 \mathrm{Ab}$ & $69,7 \mathrm{Ba}$ \\
\hline DKB 333B & - & - & - & - & $55,5 \mathrm{Bc}$ & $60,4 \mathrm{Abc}$ & $64,2 \mathrm{Aab}$ & $70,3 \mathrm{BDa}$ \\
\hline AG 1051 & - & - & - & - & $50,2 \mathrm{Cb}$ & $66,7 \mathrm{Aa}$ & $62,4 \mathrm{Aa}$ & $69,4 \mathrm{BCa}$ \\
\hline Z 8550 & - & - & - & - & $51,6 \mathrm{Cb}$ & $58,3 \mathrm{Ab}$ & $63,7 \mathrm{Aa}$ & $67,2 \mathrm{CDa}$ \\
\hline Erro-padrão & - & - & - & - & 0,66 & 3,62 & 3,50 & 0,53 \\
\hline Safra $2001 / 2002$ & - & - & - & - & $50,4 \mathrm{Bc}$ & $61,4 b$ & $58,5 \mathrm{~b}$ & $69,3 \mathrm{~B} \mathrm{a}$ \\
\hline Safra $2002 / 2003$ & - & - & - & - & $56,5 \mathrm{Ac}$ & $61,6 b$ & $63,4 b$ & $70,9 \mathrm{Aa}$ \\
\hline Erro-padrão & - & - & - & - & 0,38 & 2,09 & 2,05 & 0,31 \\
\hline
\end{tabular}

Médias seguidas de letras diferentes, maiúscula na coluna ou minúscula na linha, diferem $(\mathrm{P}<0,05)$ entre si estatisticamente pelo teste $t$ de Student.

no primeiro corte para até $55,5 \%$ de MS no último corte. No ponto considerado ideal para corte da planta $\left(5^{\circ}\right.$ e $6^{\circ}$ cortes), os teores de MS no sabugo foram 35 a 47,5\%, e foram maiores $(\mathrm{P}<0,05)$ no híbrido CO 32 e menores $(\mathrm{P}<0,05)$ no híbrido $\mathrm{P} 3041$.

Os teores de matéria seca do sabugo foram semelhantes em relação ao tempo entre os híbridos CO 32, DKB 333B e AG 1051, assim, esses híbridos foram agrupados para gerar as equações de regressão (Figura 2a). Os híbridos P 3041 e Z 8550 também apresentaram teor de MS semelhante no sabugo e foram agrupados.

O efeito quadrático do tempo de maturação sobre o teor de MS do sabugo indica que até aproximadamente 92 DAS, ocorre acentuada elevação nos teores de MS desta fração, que posteriormente se mantêm relativamente constantes, uma vez que, a partir deste ponto, todo o sabugo já está formado e os aumentos em MS passam a ocorrer nos grãos da espiga.

Russell (1986) avaliou as características da fração fibrosa de cultivares de milho para silagem e encontrou efeito linear crescente $(\mathrm{P}<0,05)$ da época de corte sobre teor de MS da folha, com aumentos diários de $0,85 \%$. Semelhante ao observado neste estudo, esse autor encontrou efeito quadrático crescente $(\mathrm{P}<0,05)$ para o teor de MS do sabugo. $\mathrm{O}$ avanço da maturação da planta aumentou $(\mathrm{P}<0,05)$ a proporção de MS do grão, que atingiu valores de aproximadamente $70 \%$ de MS no $8^{\circ}$ corte. No ponto de silagem, os teores de MS do grão variaram de 50,4 a 61,6\% nas duas safras avaliadas (Tabela 3 ). No $5^{\circ}$ e $8^{\circ}$ cortes, o híbrido CO 32 foi o material que apresentou os maiores $(\mathrm{P}<0,05)$ teores de $\mathrm{MS}$ no grão, enquanto os híbridos AG 5011 e Z 8550 foram aqueles com os menores $(\mathrm{P}<0,05)$ teores de MS do grão.

Resultados semelhantes aos observados neste estudo foram relatados por Rosa et al. (2004), que avaliaram o perfil agronômico de híbridos de milho no ponto de silagem $(29,4$ a 35,5\% MS) e verificaram teores de MS das frações sabugo e grãos, com valores de 32,1 a 41,0\%; e 42,1 a 59,3\%, respectivamente. Valores inferiores têm sido reportados na literatura, como os obtidos por Ferreira et al. (2006), entre 41,3 e 51,0\% nos grãos em híbridos e variedades de milho no ponto de silagem (plantas com 29,6 a 34,0\% de MS).

Após o florescimento da planta, com a mudança da relação fonte-dreno para a espiga, o crescimento do colmo cessa e, a partir deste estádio, as frações da planta, principalmente os grãos, acumulam MS, como resultado da translocação dos sintetizados nas folhas e no colmo (Fancelli \& Dourado Neto, 2000). Nesta pesquisa, os híbridos CO 32 e AG 1051 apresentaram teor de MS do grão semelhante (Figura 2b) e, desta forma, foram agrupados para gerar uma única equação.

Os híbridos CO 32, DKB 333B e AG 1051 apresentaram efeito linear crescente $(\mathrm{P}<0,05)$ do teor de matéria seca do grão em função do tempo. $\mathrm{O}$ aumento de um dia no estádio de maturação da planta representou elevações de $0,81 \%$ no teor de MS do grão dos híbridos CO 32 e AG 1051 e de 0,80\% no híbrido DKB 333B. Nos demais híbridos, o tempo teve efeito quadrático crescente $(\mathrm{P}<0,05)$ sobre o teor de MS do grão. 


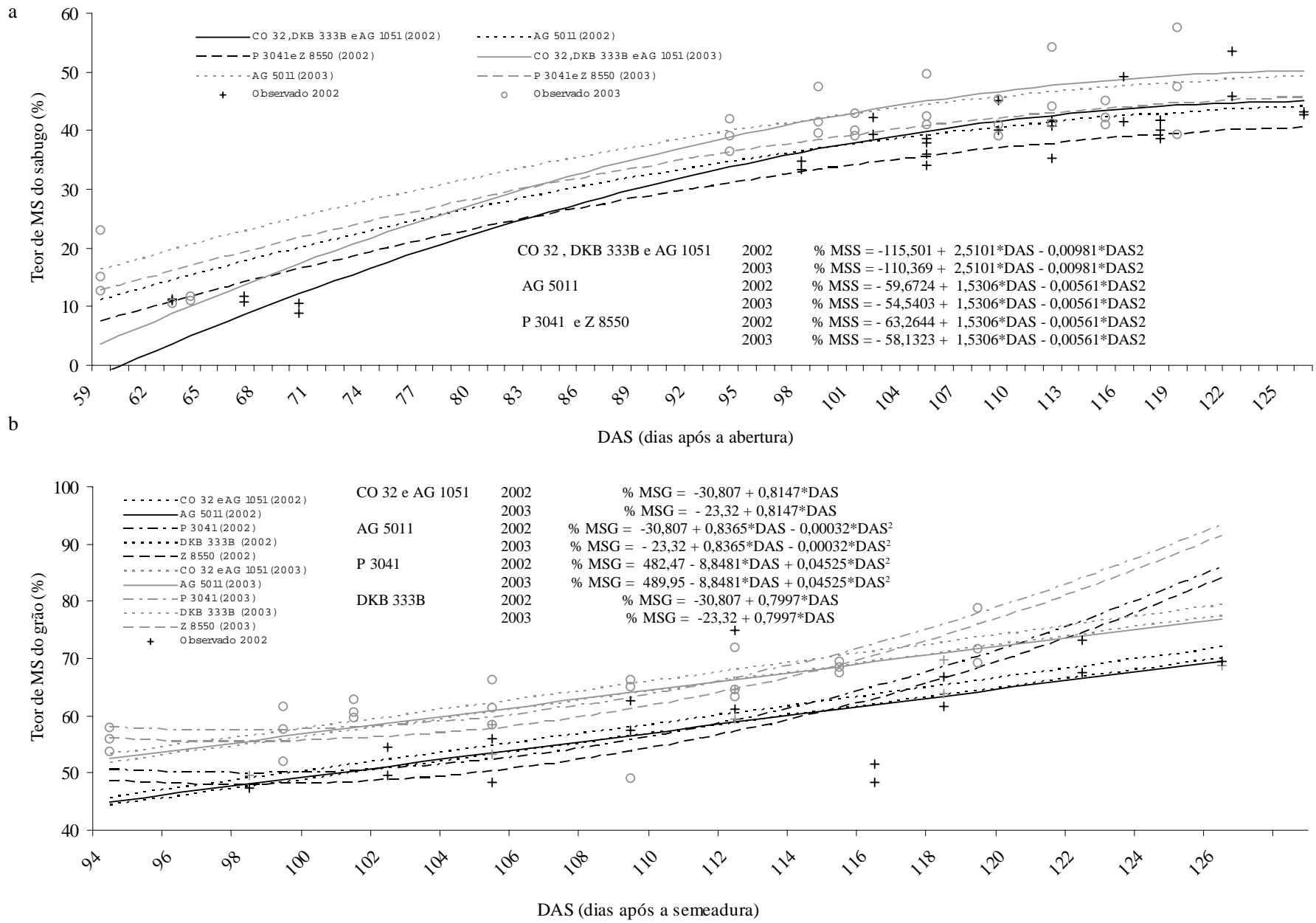

${ }^{1}$ MSS - teor de MS do sabugo; ${ }^{2}$ MSG - teor de MS do grão; DAS - dias após a semeadura.

Figura 2 - Teor de matéria seca do sabugo (a) e do grão (b) em cada época de corte.

O estádio de maturação influenciou de forma quadrática o teor de MS do grão. No entanto, os híbridos P 3041 e Z 8550 diferiram dos demais, pois, até aproximadamente 104 DAS, tiveram pequenos aumentos no teor de MS do grão, mas posteriormente apresentaram aumentos significativos, ultrapassando os demais híbridos. Portanto, a taxa de acúmulo de MS no grão dos híbridos avaliados apresenta diferentes padrões, o que representa um critério adicional na escolha do híbrido a ser utilizado na produção de silagem.

Resultados semelhantes ao deste estudo foram observados por Rosa et al. (2004), que avaliaram o perfil agronômico de híbridos de milho para silagem quando os grãos se encontravam entre o final do estádio pastoso e o início do estádio farináceo (planta com 35,5\% MS) e observaram no híbrido AG 5011 teores de 41,0 a 59,3\% no sabugo e nos grãos, respectivamente.

O híbrido CO 32 foi o que apresentou os maiores $(\mathrm{P}<0,05)$ teores de MS em todas as frações da planta estudadas. Portanto, para este material, o ponto de corte para produção de silagem é provavelmente antecipado, visto que os teores de MS da planta e do colmo também são normalmente superiores para este híbrido, como demonstrado por Zopollatto (2007).

$\mathrm{O}$ avanço do estádio de maturação da planta resultou em aumentos $(\mathrm{P}<0,05)$ na proporção de colmo na planta até o $4^{\circ}$ corte na safra 2001/2002 e até o $3^{\circ}$ corte na safra 2002/ 2003 (Tabela 4). Posteriormente, a proporção de colmo manteve-se constante até o $7^{\circ}$ corte na safra 2001/2002 e até o $6^{\circ}$ corte na safra 2002/2003, reduzindo $(\mathrm{P}<0,05)$ após estas épocas.

Com exceção do $3^{\circ}$ corte, a participação de colmo na planta nas duas safras avaliadas foi similar entre os cortes e, no ponto de silagem, foi de 34 a 35,6\%. O conhecimento da participação das frações da planta em sua composição é fundamental, principalmente a de colmo, que não representa somente um suporte para as folhas e inflorescências, mas trata-se de uma estrutura destinada ao armazenamento de sólidos solúveis que serão utilizados na formação dos grãos (Fancelli \& Dourado Neto, 2000). 
Tabela 4 - Proporção média de matéria seca acumulada nas partes da planta em cada época de corte

\begin{tabular}{|c|c|c|c|c|c|c|c|c|}
\hline \multirow[t]{2}{*}{ Híbrido } & \multicolumn{8}{|c|}{ Corte } \\
\hline & 1 & 2 & 3 & 4 & 5 & 6 & 7 & 8 \\
\hline \multicolumn{9}{|l|}{ Colmo } \\
\hline Safra $2001 / 2002$ & $63,4 \mathrm{a}$ & $47,7 b$ & $41,2 \mathrm{Ac}$ & $33,8 \mathrm{~d}$ & $35,2 \mathrm{~d}$ & $34,0 \mathrm{~d}$ & $33,4 \mathrm{~d}$ & $29,5 \mathrm{e}$ \\
\hline Safra $2002 / 2003$ & $62,4 \mathrm{a}$ & - & $35,8 \mathrm{Bb}$ & $36,3 b$ & $35,0 \mathrm{~b}$ & $35,6 b$ & $30,9 \mathrm{c}$ & $30,4 \mathrm{c}$ \\
\hline Erro-padrão & 0,49 & 1,03 & 0,88 & 0,95 & 0,55 & 0,63 & 1,06 & 0,66 \\
\hline \multicolumn{9}{|l|}{ Folhas } \\
\hline $\mathrm{CO} 32$ & $27,4 \mathrm{ABa}$ & - & $16,2 \mathrm{Bb}$ & $13,2 \mathrm{Bc}$ & $13,5 \mathrm{Cc}$ & $12,3 \mathrm{Cd}$ & $11,1 \mathrm{Bde}$ & $9,9 \mathrm{Be}$ \\
\hline AG 5011 & $28,8 \mathrm{Aa}$ & - & $20,9 \mathrm{Ab}$ & $16,1 \mathrm{Ac}$ & $16,2 \mathrm{Ac}$ & $15,2 \mathrm{Acd}$ & $14,1 \mathrm{Ade}$ & $12,7 \mathrm{Ae}$ \\
\hline P 3041 & $28,0 \mathrm{Aa}$ & - & $17,0 \mathrm{Bb}$ & $13,5 \mathrm{Bd}$ & $14,9 \mathrm{ABbc}$ & $14,2 \mathrm{ABcd}$ & $11,8 \mathrm{Bd}$ & $10,1 \mathrm{Be}$ \\
\hline DKB 333B & $26,0 \mathrm{BCa}$ & - & $14,4 \mathrm{Bbc}$ & $13,5 \mathrm{Bb}$ & $14,2 \mathrm{BCb}$ & $13,6 \mathrm{BCb}$ & $12,0 \mathrm{Bc}$ & $14,5 \mathrm{Ab}$ \\
\hline AG 1051 & $25,3 \mathrm{Ca}$ & - & $15,7 \mathrm{Bb}$ & $13,4 \mathrm{Bb}$ & $14,0 \mathrm{BCb}$ & $14,1 \mathrm{ABb}$ & $11,9 \mathrm{Bc}$ & $10,2 \mathrm{Bd}$ \\
\hline Z 8550 & $28,4 \mathrm{Aa}$ & - & $17,2 \mathrm{Bbc}$ & $14,4 \mathrm{Bd}$ & $16,1 \mathrm{Ab}$ & $14,6 \mathrm{ABcd}$ & $11,9 \mathrm{Be}$ & $10,5 \mathrm{Be}$ \\
\hline Erro-padrão & 0,71 & - & 1,24 & 0,56 & 0,47 & 0,52 & 0,62 & 0,63 \\
\hline Safra $2001 / 2002$ & $27,5 \mathrm{a}$ & $20,4 b$ & $17,0 \mathrm{c}$ & $13,3 \mathrm{Bde}$ & $13,8 \mathrm{Bd}$ & $13,2 \mathrm{Bde}$ & $12,4 \mathrm{e}$ & $10,8 \mathrm{Bf}$ \\
\hline Safra $2002 / 2003$ & $27,1 \mathrm{a}$ & - & $16,8 \mathrm{~b}$ & $14,7 \mathrm{Ac}$ & $15,8 \mathrm{Ab}$ & $14,8 \mathrm{Ac}$ & $11,9 \mathrm{~d}$ & $11,8 \mathrm{Ad}$ \\
\hline Erro-padrão & 0,41 & 0,69 & 0,72 & 0,32 & 0,27 & 0,30 & 0,36 & 0,36 \\
\hline \multicolumn{9}{|l|}{ Sabugo } \\
\hline $\mathrm{CO} 32$ & $2,6 \mathrm{Ac}$ & - & - & - & $8,7 \mathrm{Ba}$ & $8,2 \mathrm{Db}$ & $8,7 \mathrm{Bab}$ & $8,0 \mathrm{BCab}$ \\
\hline AG 5011 & $1,7 \mathrm{Bc}$ & - & - & - & $10,5 \mathrm{Aa}$ & $9,6 \mathrm{Ab}$ & $9,8 \mathrm{Aab}$ & $9,2 \mathrm{Ab}$ \\
\hline P 3041 & $1,6 \mathrm{Bd}$ & - & - & - & 9,9Aa & $9,1 \mathrm{Bbc}$ & 9,7Aab & $8,8 \mathrm{ABc}$ \\
\hline DKB 333B & $2,0 \mathrm{ABc}$ & - & - & - & $9,8 \mathrm{Aa}$ & $8,9 \mathrm{BCb}$ & $8,4 \mathrm{Bb}$ & $9,0 \mathrm{Ab}$ \\
\hline AG 1051 & $2,0 \mathrm{ABc}$ & - & - & - & $7,5 \mathrm{Ca}$ & 7,1Eab & $7,2 \mathrm{Cab}$ & $6,6 \mathrm{Db}$ \\
\hline Z 8550 & $2,3 \mathrm{ABd}$ & - & - & - & $9,9 \mathrm{Aa}$ & $8,5 \mathrm{CDb}$ & $8,3 \mathrm{Bbc}$ & $7,7 \mathrm{Cc}$ \\
\hline Erro-padrão & 0,25 & - & - & - & 0,23 & 0,17 & 0,35 & 0,29 \\
\hline
\end{tabular}

Médias seguidas de letras diferentes, maiúscula na coluna ou minúscula na linha, diferem entre si $(\mathrm{P}<0,05)$ pelo teste $\mathrm{t}$ de Student.

A proporção de colmo nos períodos de avaliação foi similar entre os híbridos CO 32 e Z 8550, AG 5011 e P 3041, por isso, esses cultivares foram agrupados na elaboração das equações de regressão (Figura 3a). Em todos os híbridos, o tempo teve efeito quadrático decrescente $(\mathrm{P}<0,05)$ sobre a proporção de colmo.

Beleze et al. (2003) verificaram efeito cúbico $(\mathrm{P}<0,05)$ do tempo na proporção de colmo+bainha de híbridos de milho colhidos em diversos estádios de maturação. Neste estudo, o avanço da maturação da planta reduziu $(\mathrm{P}<0,05)$ a participação de folhas, que passou de $27,5 \%$ no primeiro corte para $10,8 \%$ no último corte. Na safra 2002/2003, as proporções de folha aumentaram $(\mathrm{P}<0,05)$ na maioria dos cortes (Tabela 4$)$.

No ponto de silagem, as proporções de folha variaram entre 13,2 e $13,8 \%$ na safra 2001/2002 e entre 14,7 e $15,8 \%$ na safra 2002/2003. Costa et al. (2000) avaliaram as características agronômicas de 12 cultivares de milho para silagem colhidos quando o grão se encontrava com 3/4 da linha de leite e verificaram proporções de 38,7 a $46,7 \%$ de colmo na planta. A participação de colmos obtida neste estudo foi inferior, mas a participação de folhas foi muito semelhante às obtidas por esses autores (11,4 a 15,4\%).

Nos híbridos AG 5011, P 3041 e AG 1051, as participações de colmos e folhas foram próximas e variaram 1,0 a 2,0\% entre os trabalhos. O híbrido AG 5011 foi o que apresentou as maiores proporções de folha na planta (12,7 a 28,8\%). Nos híbridos AG 5011 e P 3041, a proporção de folhas foi semelhante entre os períodos de avaliação, assim, foram agrupados para gerar as equações de regressão (Figura 3b). Esta semelhança também foi observada para os híbridos AG 1051 e Z 8550, que também foram agrupados.

O estádio de maturação teve efeito quadrático decrescente $(\mathrm{P}<0,05)$ sobre a participação de folhas nos híbridos avaliados. Antoniali et al. (2003) realizaram a análise morfológica dos híbridos de milho para silagem DKB 333B e Z 8550 colhidos quando a linha do leite se apresentava entre 1/3 e 2/3 do grão e observaram proporções de folhas e colmo para os híbridos DKB 333B e Z 8550 de 15,4 e 13,9\%; e 21,5 e $17,8 \%$, respectivamente. Neste estudo, no entanto, a linha de leite entre $1 / 3$ e $2 / 3$ do grão foi obtida entre o $3^{\circ}$ e o $5^{\circ}$ corte.

$\mathrm{O}$ avanço da maturação da planta ocasionou aumento $(\mathrm{P}<0,05)$ na proporção de sabugo, que passou de $1,6 \%$ no primeiro corte para $9,2 \%$ no $8^{\circ}$ corte. A partir do $5^{\circ}$ corte, a proporção de sabugo sofreu pequenas alterações, no máximo 2,0\%, como observado para o híbrido Z 8550 (Tabela 4).

No ponto de silagem, os híbridos de milho apresentaram entre 7,1 e 10,5\% de sabugo na planta. As maiores $(\mathrm{P}<0,05)$ participações foram observadas no híbrido AG 5011, seguido dos híbridos P 3041 e DKB 333B, e as menores ( $\mathrm{P}<0,05)$, 

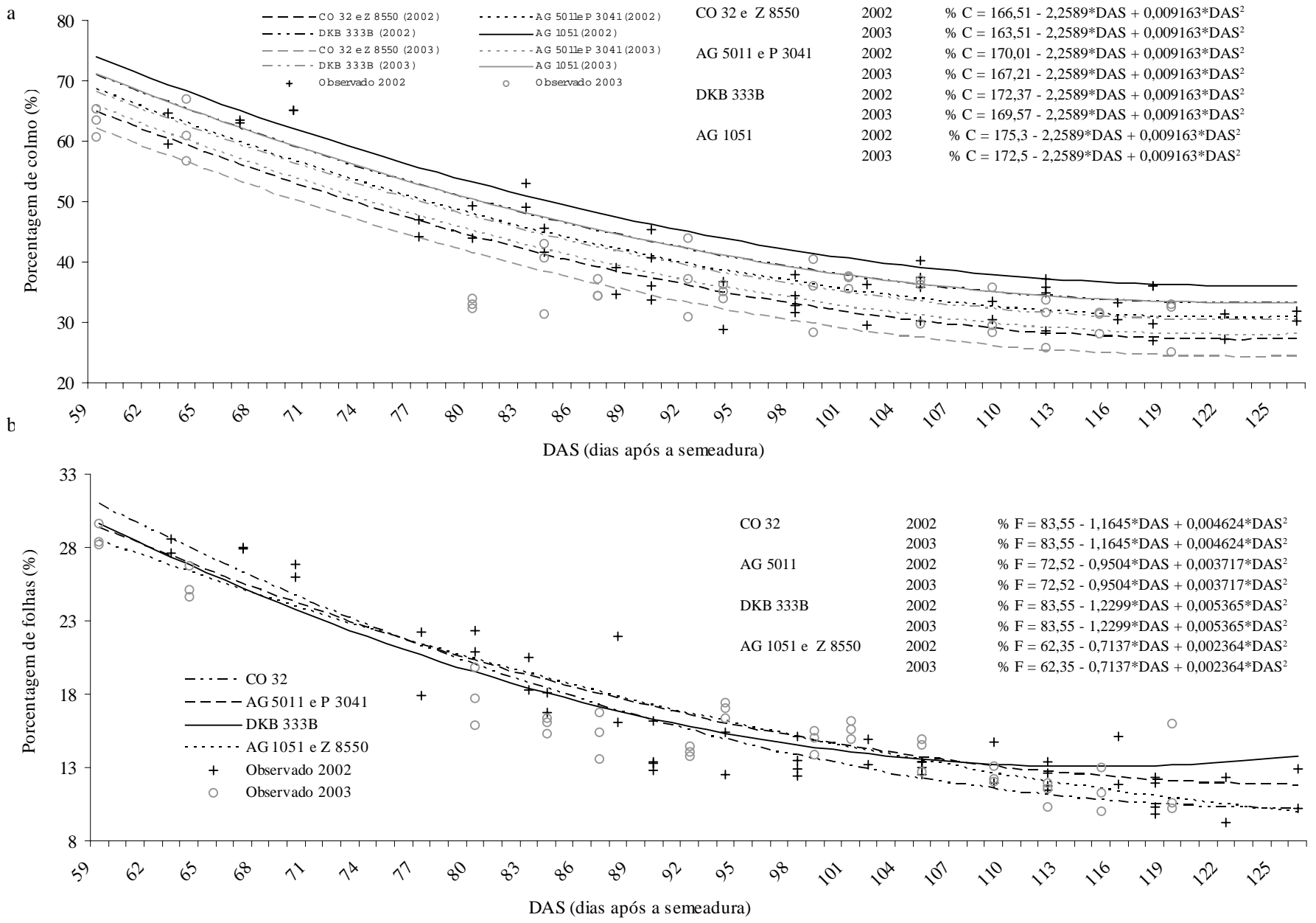

${ }^{1} \mathrm{C}$ - Proporção de colmo; ${ }^{2} \mathrm{~F}$ - Proporção de folha; DAS - dias após a semeadura.

Figura 3 - Participação de colmo (a) e das folhas (b) dos híbridos de milho em cada época de corte.

no híbrido AG 1051. O aumento da fração sabugo contribui para a diminuição do valor nutritivo da forragem, pois esta fração é constituída de parede celular de baixa qualidade, característica que pode ser utilizada como critério de seleção de cultivares, visando obter plantas com menores participações desta fração ou com melhor valor nutritivo desta fração.

A participação de sabugo nos híbridos CO 32 e AG 1051 foi semelhante entre as épocas de corte, por isso, esses cultivares foram agrupados para gerar as equações de regressão (Figura 4a). Da mesma forma, os híbridos AG 5011, P 3041 e DKB 333B também foram agrupados pela semelhança na participação de sabugo na planta.

Em todos os híbridos avaliados, o estádio de maturação teve efeito quadrático crescente $(\mathrm{P}<0,05)$ na proporção de matéria seca acumulada no sabugo. $\mathrm{O}$ avanço da idade ocasionou aumentos decrescentes na fração sabugo da planta.

Beleze et al. (2003) verificaram perfil linear e quadrático decrescentes $(\mathrm{P}<0,05)$ para a proporção de MS acumulada nas folhas com o avançar do estádio de maturação da planta. Esses autores verificaram ainda efeito quadrático crescente $(\mathrm{P}<0,05)$ do tempo sobre as frações sabugo+brácteas. A porcentagem de MS acumulada nos grãos não variou com as interações ano $\times$ corte $\times$ híbrido, por isso, esses efeitos foram avaliados individualmente (Tabela 5).

A proporção de matéria seca acumulada nos grãos foi maior $(\mathrm{P}<0,05)$ no híbrido $\mathrm{CO} 32$ e similar entre os demais cultivares. A safra 2002/2003 apresentou maiores proporções de grãos em relação à safra 2001/2002. As maiores $(\mathrm{P}<0,05)$ participações das frações folha e grãos na safra $2002 / 2003$ estão relacionadas aos maiores $(P<0,05)$ teores de MS nestas frações.

Apesar da maior proporção de MS acumulada nos grãos no híbrido CO 32, isso não resulta especificamente em maiores produções de grãos (kg MS/ha) nesse cultivar, como observado por Zopollatto (2007), desta forma, a escolha do híbrido de milho baseada somente na proporção de grãos pode ser errônea, pois não indica maior produção de grãos. 


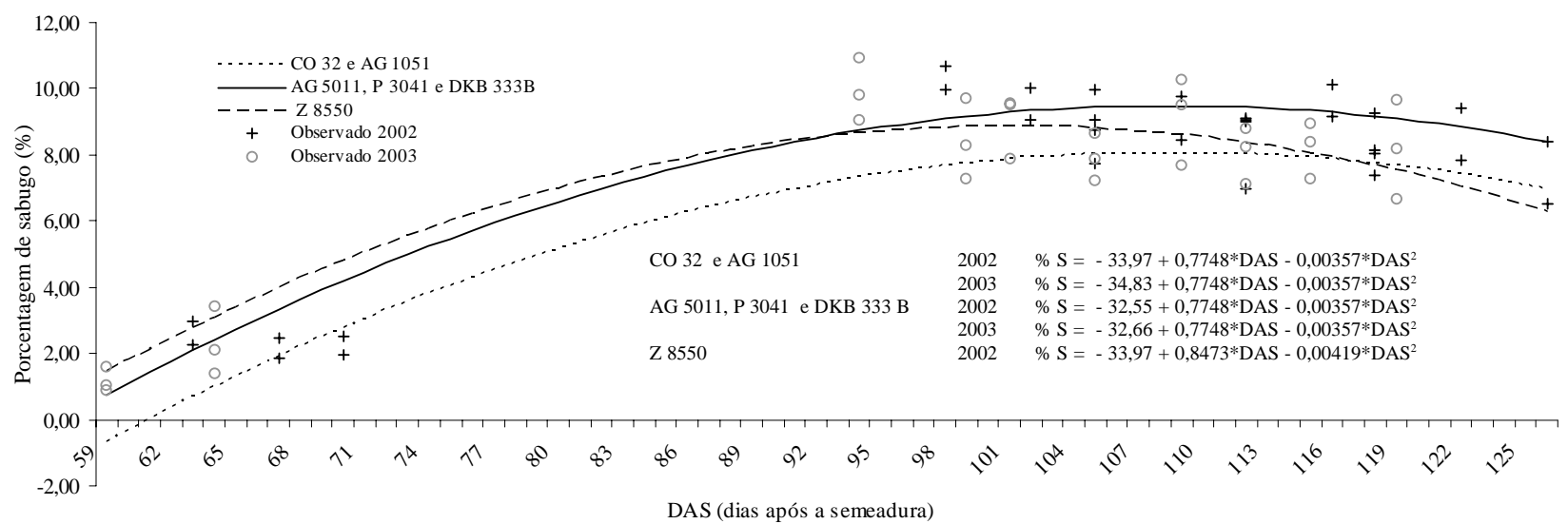

$\mathrm{b}$

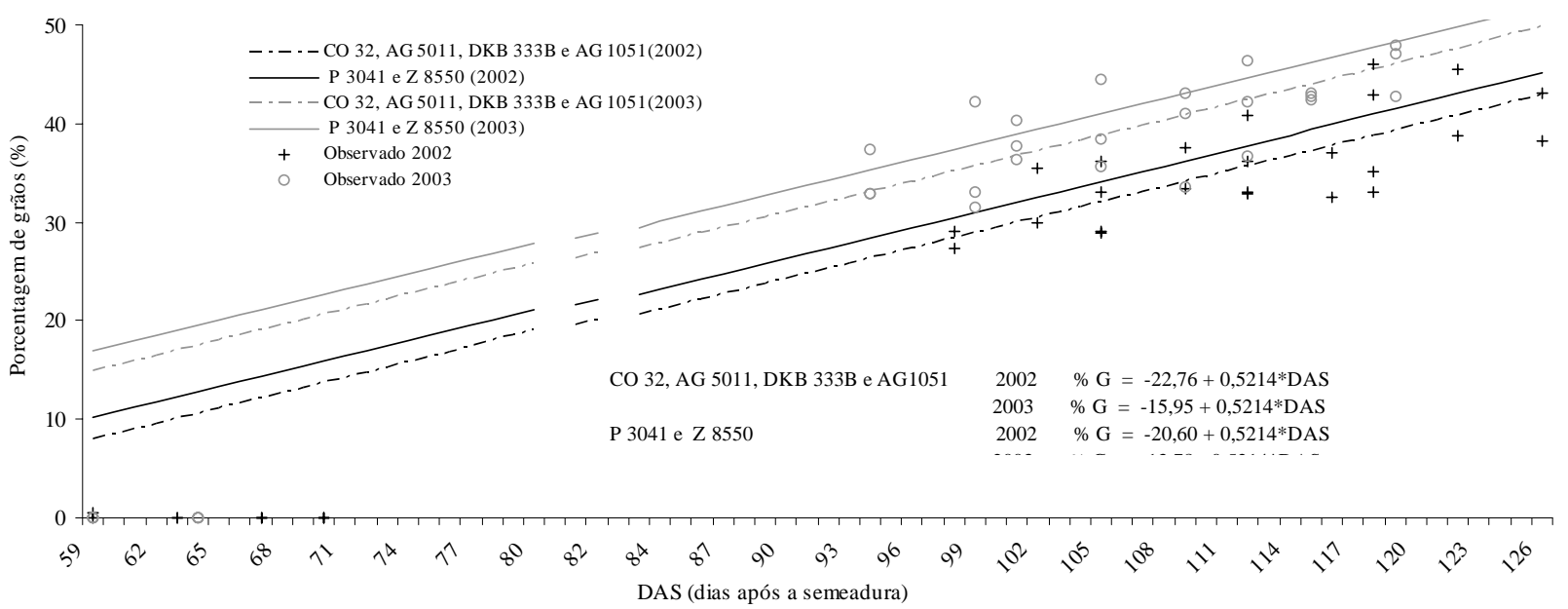

${ }^{1} \mathrm{~S}$ - Proporção de matéria seca acumulada no sabugo; ${ }^{2} \mathrm{G}$ - Proporção de grãos; DAS - dias após a semeadura.

Figura 4 - Curvas de regressão da proporção de matéria seca acumulada no sabugo (a) e de grãos (b) em cada época de corte.

Tabela 5 - Participação média de matéria seca acumulada nos grãos ao longo dos cortes

\begin{tabular}{|c|c|c|c|c|c|c|c|c|}
\hline \multirow[t]{2}{*}{ Híbrido } & \multicolumn{8}{|c|}{ Corte } \\
\hline & 1 & 2 & 3 & 4 & 5 & 6 & 7 & 8 \\
\hline Grão (\%) & - & - & - & - & $32,4 \mathrm{c}$ & $36,6 b$ & $38,1 \mathrm{~b}$ & $43,4 \mathrm{a}$ \\
\hline \multirow[t]{2}{*}{ Erro-padrão } & - & - & - & - & 0,40 & 0,52 & 1,16 & 0,71 \\
\hline & \multicolumn{4}{|c|}{ Safra $2001 / 2002$} & \multicolumn{4}{|c|}{ Safra $2002 / 2003$} \\
\hline $\begin{array}{l}\text { Grão (\%) } \\
\text { Erro-padrão }\end{array}$ & \multicolumn{4}{|c|}{$35,6 b$} & \multicolumn{4}{|c|}{$39,6 a$} \\
\hline \multirow{2}{*}{ Erro-padrão } & & \multicolumn{5}{|c|}{ Híbrido } & & \\
\hline & & $\mathrm{CO} 32$ & AG 5011 & P 3041 & DKB 333B & AG 1051 & Z 8550 & \\
\hline Grão (\%) & & $41,9 \mathrm{a}$ & $35,9 b$ & $36,7 b$ & $35,8 \mathrm{~b}$ & $36,9 b$ & $38,6 \mathrm{~b}$ & \\
\hline Erro-padrão & & 1,03 & 1,03 & 1,03 & 1,03 & 1,08 & 1,03 & \\
\hline
\end{tabular}

Médias seguidas de letra diferente na linha, diferem entre si estatisticamente $(\mathrm{P}<0,05)$ pelo teste $t$ de Student.

Para o híbrido P 3041 colhido com aproximadamente $40 \%$ de MS aos 156 DAS, Beleze et al. (2003) observaram proporções de grãos bem superiores, em torno de 54,5\%. Entretanto, este híbrido atingiu o teor de $40 \%$ de MS da planta por volta de 110 DAS.

$\mathrm{O}$ avanço da maturação resultou em aumento $(\mathrm{P}<0,05)$ da proporção de grãos de $11 \%$ do $5^{\circ}$ ao $8^{\circ}$ corte. No ponto de silagem, a proporção de grãos na planta variou entre 32,4 e $36,6 \%$.

Thomas et al. (2001) encontraram contribuições menores de colmo (23,2 a 25,8\%), folhas (10,2 a 12,3\%) e sabugo (6,5 a $7,4 \%)$ e maiores de grão $(49,8$ a $53,4 \%)$. Entretanto, as plantas foram colhidas com teores de MS mais elevados, cerca de $40 \%$ MS, níveis que foram atingidos somente a 
partir do $7^{\underline{0}}$ corte (109 a 118 DAS). Jaremtchuk et al. (2005) também verificaram valores mais baixos para as frações colmo (18,1 a 24,9\%) e mais altos para a fração folha (21,7 a $30,9 \%$ ) em plantas colhidas com grãos apresentando $1 / 3$ da linha do leite.

A proporção de grão nos estádios de maturação da planta apresentou perfil semelhante entre os híbridos CO 32, AG 5011, DKB 333B e AG 1051, mesmo comportamento observado entre os híbridos P 3041 e Z 8550 para esta variável.

Os híbridos de milho apresentaram efeito linear crescente $(\mathrm{P}<0,05)$ para a proporção de grãos em cada estádio de maturação (Figura 4 b). Para cada dia de avanço na idade da planta, observaram-se aumentos de $0,5 \%$ na proporção de grãos.

$\mathrm{O}$ efeito linear crescente $(\mathrm{P}<0,05)$ observado para a proporção de grãos na planta também foi verificado por Beleze et al. (2003), com aumentos diários médios de $0,42 \%$, próximos aos aumentos encontrados neste estudo.

Há grande variabilidade entre os cultivares, tanto na porcentagem de MS como na participação das frações na composição final da planta, o que evidencia a característica intrínseca de cada híbrido avaliado. Desta forma, não é possível o estabelecimento de um perfil padrão na definição do momento de colheita mais adequado da planta para ensilagem. Assim, destaca-se a importância de uma seleção criteriosa do híbrido de milho a ser escolhido em programas de avaliação de cultivares para silagem.

\section{Conclusões}

No ponto de ensilagem, colmo e grãos são os componentes de maior participação na composição da planta, sobretudo no híbrido CO 32, de ciclo precoce, que possui maior participação de grãos na composição da planta. O teor de MS das frações e a participação percentual dessas frações na composição da planta variam entre os híbridos avaliados. A comparação de plantas colhidas em estádios fisiológicos com base na participação das frações deve ser feita com muito critério, uma vez que a época de corte pode alterar significativamente a composição morfológica da planta.

\section{Agradecimentos}

À Apta Regional, pelo apoio para a realização deste trabalho. À CAPES, pela concessão de bolsa de estudos. À equipe de Qualidade e Conservação de Forragem da USP/ ESALQ, pelo apoio nos trabalhos de campo.

\section{Literatura Citada}

ANTONIALI, M.; REIS, R.A.; MOREIRA, A.L. et al. Avaliação de cultivares de milho (Zea mays L.) para a produção de silagem: produção de matéria seca e análise morfológica. In: REUNIÃO ANUAL DA SOCIEDADE BRASILEIRA DE ZOOTECNIA, 40. 2003, Santa Maria. Anais... Santa Maria: Sociedade Brasileira de Zootecnia, 2000. (CD-ROM).

BELEZE, J.R.F.; ZEOULA, L.M.; CECATO, U. et al. Avaliação de cinco híbridos de milho (Zea mays L.) em diferentes estádios de maturação. 2. Concentrações dos componentes estruturais e correlações. Revista Brasileira de Zootecnia, v.32, n.3, p.538-545, 2003.

COSTA, R.S.; RODRIGUES, J.A.S.; GONÇALVES, L.C. et al. Características agronômicas de doze cultivares de milho para silagem. In: REUNIÃO ANUAL DA SOCIEDADE BRASILEIRA DE ZOOTECNIA, 37., 2000, Viçosa, MG. Anais...Viçosa, MG: Sociedade Brasileira de Zootecnia, 2000. (CD-ROM).

FANCELli, Al.; DOURADO NETO, D. Produção de milho. Guaíba: Agropecuária, 2000. 360p.

FERREIRA, J.J. Características qualitativas e produtivas da planta de milho e sorgo para silagem. In: CRUZ, J.C.; PEREIRA FILHO, I.A.; RODRIGUES, J.A.S. et al. (Eds.) Produção e utilização de silagem de milho e sorgo. Sete Lagoas: Embrapa Milho e Sorgo, 2001. p.383-404.

FERREIRA, J.J.; RUAS, J.R.M.; SILVA, E.A. et al. Produção de grãos e fração fibrosa por diferentes cultivares de milho nos estágios de silagem e maturação completa. In: REUNIÃO ANUAL DA SOCIEDADE BRASILEIRA DE ZOOTECNIA, 43. 2006, João Pessoa. Anais... João Pessoa: Sociedade Brasileira de Zootecnia, 2006. (CD-ROM).

HUNTER, R.B. Selection and evaluation procedures for wholeplant corn silage. Canadian Journal of Plant Science, v. 58 n.7, p.661-678, 1978.

JAREMTCHUK, A.R.; JAREMTCHUK, C.C.; BAGLIOLI, B. et al. Características agronômicas e bromatológicas de vinte genótipos de milho (Zea mays L.) para silagem na região leste paranaense. Acta Scientiarum.Animal Science, v.27, n.2, p.181-188, 2005. NEUMANN, M.; OST, P.R.; LUSTOSA, S.B.C. et al Comportamento produtivo de híbridos de milho (Zea mays L.) e sorgo (Sorghum bicolor) para produção de silagem. In: REUNIÃO ANUAL DA SOCIEDADE BRASILEIRA DE ZOoteCniA, 43., 2006, João Pessoa. Anais... João Pessoa: Sociedade Brasileira de Zootecnia, 2006. (CD-ROM).

PEREIRA, M.N.; VON PINHO, R.G.; BRUNO, R.G.S. et al. Ruminal degradability of hard or soft texture corn grain at three maturity stages. Scientia Agricola, v.61, n.4, p.358-363, 2004.

ROSA, J.R.P.; RESTLE, J.; SILVA, J.H.S. et al. Avaliação da silagem de diferentes híbridos de milho (Zea mays L.) por meio do desempenho de bezerros confinados em fase de crescimento Revista Brasileira de Zootecnia, v.33, n.4, p.1016-1028, 2004.

RUSSELL, J.R. Influence of harvest date on the nutritive value and ensiling characteristics of maize stover. Animal Feed Science and Technology, v.14, p.11-27, 1986.

THOMAS, E.D.; MANDEBVU, P.; BALLARD, C.S. et al Comparison of corn silage hybrids for yield, nutrient composition, in vitro digestibility, and milk yield by dairy cows. Journal of Dairy Science, v.84, n.10, p.2217-2226, 2001.

WOLF, D.P.; COORS, J.G.; ALBRECHT, K.A. et al. Agronomic evaluations of maize genotypes selected for extreme fiber concentrations. Crop Science, v.33, n.6, p.1359-1365, 1993

ZOPOLlATTO, M. Avaliação do efeito da maturidade de cultivares de milho (Zea mays $\mathbf{L}$.) para silagem sobre a produtividade, composição morfológica e valor nutritivo da planta e seus componentes. 2007. 210f. Tese (Doutorado em Agronomia) - Escola Superior de Agricultura "Luiz de Queiroz", Piracicaba, 2007. 